\title{
Chemical design of onion-like carbon-silicon diimide polymer composites
}

\author{
Kaili Wang ${ }^{1}$ and Gabriela Mera ${ }^{2 * *}$ (1) \\ ${ }^{1}$ Fachbereich Biochemie, Chemie und Pharmazie, Goethe-Universität Frankfurt am Main, Frankfurt, Germany, and Institut für \\ Materialwissenschaft, Technische Universität Darmstadt, Darmstadt, Germany \\ ${ }^{*}$ Corresponding author. E-mail: gabriela.mera@tu-darmstadt.de
}

(Received 03 April 2021; Revised 16 June 2021; Accepted 16 June 2021)

\begin{abstract}
Herein, we report the synthesis and characterization of a novel class of polymer composites based on onion-like carbons (OLCs)-silicon diimide by a salt-free polycondensation reaction. The pyridinecatalyzed polymerization reaction was carried out in the presence of various contents $(0.1,0.5,1$, and $2 \mathrm{wt} \%$ ) of carboxyl-functionalized OLCs in argon atmosphere to provide composites with well-dispersed and covalently incorporated $0 \mathrm{D}$ nanocarbons throughout the 3D matrix of silicon diimide polymer. A strong dependency of the optical properties (UV absorbance and the photoluminescence spectra) on the content of functionalized OLCs incorporated within the polymer matrix was observed. The novel polymer composites are suitable precursors for the design of advanced and multifunctional 0D-nanocarboncontaining $\mathrm{Si}_{3} \mathrm{~N}_{4}$-based ceramic nanocomposites.
\end{abstract}

Keywords: 0D-nanocarbon; onion-like carbons; polymer-derived ceramic composites; silicon diimide; silicon nitride

\section{Introduction}

There is a high demand for novel precursors for polymer-derived silicon nitride ceramic $\left(\mathrm{Si}_{3} \mathrm{~N}_{4}-\mathrm{PDCs}\right)$ with high mechanical, thermal, and electrical properties. Thus, several synthesis routes have been reported in the last 30 years (Balazsi, 2010, 2012; Colombo et al., 2010; Mera et al., 2013, 2015; Mera \& Ionescu, 2013, 2019; Riedel et al., 2006; Weinmann et al., 2013). By the incorporation of nanocarbons into the polymeric structure of the precursors, tunable and multifunctional properties for $\mathrm{Si}_{3} \mathrm{~N}_{4}-\mathrm{PDCs}$ can be easily accessed. Polymer composites consisting of nanosized allotropes of carbon, such as fullerenes, nanotubes, and graphene, have been reported (Balazsi, 2012; Wang et al., 2016). Chemical functionalization of nanocarbons surface offers the possibility to develop advanced polymer composites with covalent bonding (strong interface), and excellent dispersion of nanocarbon phase within the matrix (Mohamed et al., 2013). Thus, classical challenge of agglomeration of nanocarbons in the polymer matrix can be solved.

\section{Objective}

The main objective of this study is to provide a chemical facile access to novel 0D-nanocarboncontaining $\mathrm{Si}_{3} \mathrm{~N}_{4}$-based PDCs precursors, based on onion-like carbons (OLCs) (Bartelmess \& Giordani,

\footnotetext{
(C) The Author(s), 2021. Published by Cambridge University Press. This is an Open Access article, distributed under the terms of the Creative Commons Attribution licence (http://creativecommons.org/licenses/by/4.0), which permits unrestricted re-use, distribution and reproduction, provided the original article is properly cited.
} 
2014; Butsyk et al., 2019; Krüger, 2010; Kuznetsov et al., 1994; Mcdonough \& Gogotsi, 2013; Mykhailiv et al., 2017; Plonska-Brzezinska, 2019; Zeiger et al., 2016) -silicon diimide polymer composites. To achieve this objective, the salt-free pyridine-catalyzed transamination reaction of tetrachlorosilane $\left(\mathrm{SiCl}_{4}\right)$ with hexamethyldisilazane (HMDS) was made in the presence of different contents of carboxylfunctionalized OLCs (e.g., 0.1, 0.5, 1, and $2 \mathrm{wt} \%$ OLCs), using a similar procedure as previously reported for graphene oxide-silicon diimide polymer composites (Wang et al., 2016). The chemically functionalized OLCs were prepared through the oxidation reaction of pristine OLCs in the presence of concentrated nitric acid.

The in situ polymerization reaction is expected to provide an efficient access to well-dispersed OLC-containing silicon diimide polymer composites, with covalent interfacial bonding between the components.

\section{Methods}

The preparation route used in this study is described in Figure 1. Further details are provided at Wang and Mera (2021).

Pristine OLCs were obtained by the thermal graphitization of commercially available nanodiamonds (Diamond nanopowder, $<10 \mathrm{~nm}$ particle size, Merck) at $1,800^{\circ} \mathrm{C}$ in argon atmosphere. The chemical functionalization of OLCs was performed using a slightly modified oxidation process as compared with the reported (Bartelmess \& Giordani, 2014). Thus, OLCs were refluxed for $3 \mathrm{hr}$ in concentrated $\mathrm{HNO}_{3}$, washed with water and then dried in vacuum, dispersed in toluene, and stirred in ultrasonic bath for 30 min (Figure 1).

The synthesis of silicon diimide was performed as reported by Wang and Mera (2021), using an improved synthesis protocol based on the published report by Wang et al. (2016), by reacting $\mathrm{SiCl}_{4}$ with

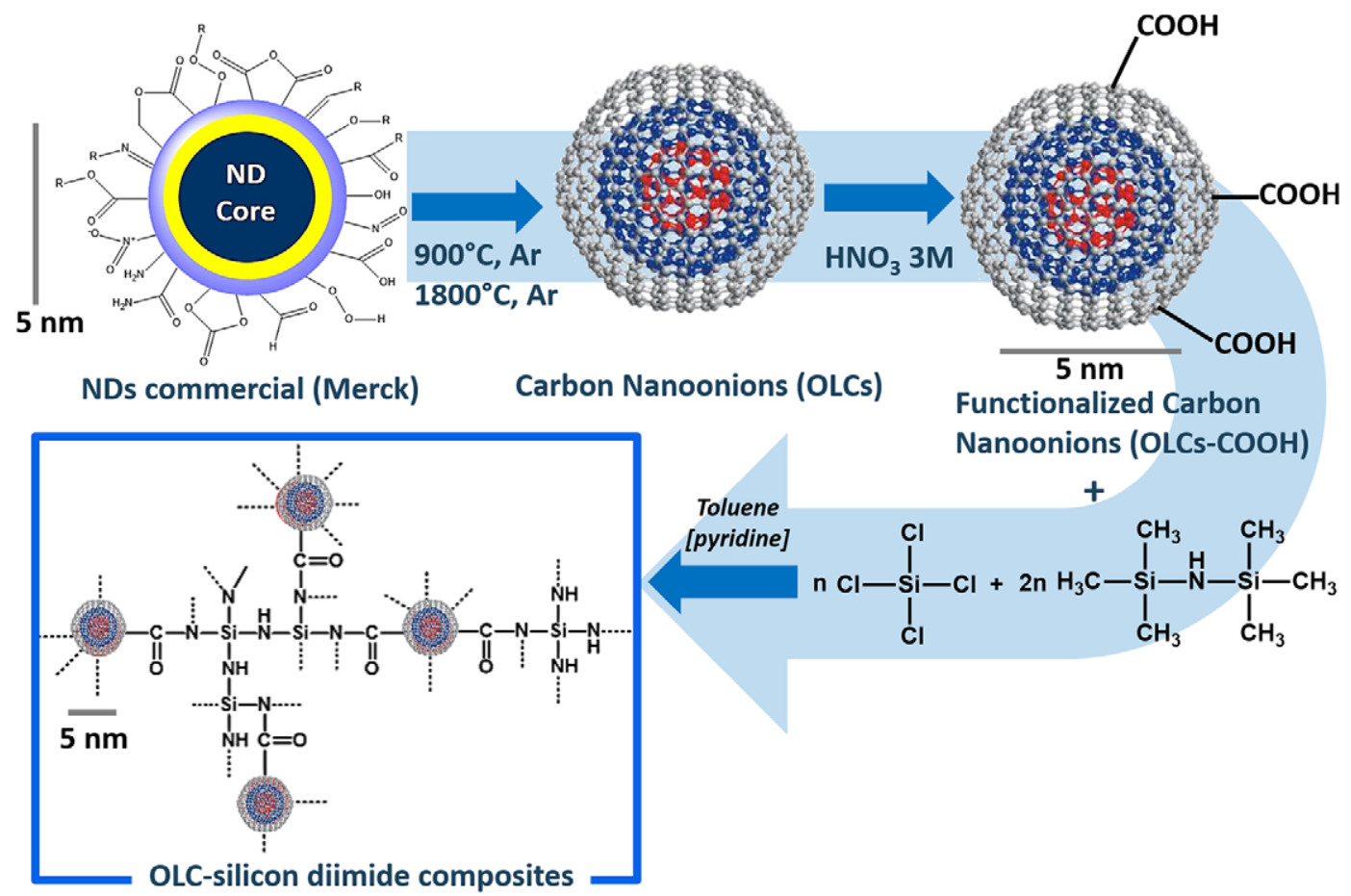

Figure 1. Synthesis of onion-like carbon (OLC)-silicon diimide composites starting from commercial nanodiamonds and their graphitization and chemical functionalization by carboxyl groups, followed by polycondensation reaction with silicon tetrachloride and hexamethyldisilazane. 
HMDS under argon atmosphere, using Schlenk technique (Figure 1). For the synthesis of nanocomposites, HMDS and the catalyst pyridine were mixed with a dispersion of OLCs in toluene, then $\mathrm{SiCl}_{4}$ was added dropwise and the solution was stirred at $0^{\circ} \mathrm{C}$ for $2 \mathrm{hr}$ in ice bath.

The insoluble and moisture-sensitive polymer composites were stored under protective atmosphere of argon (in glove box) and analyzed using different spectroscopic methods (as reported by Wang \& Mera, 2021) such as Fourier transform infrared (FTIR)-, Raman-, UV-Vis/NIR-, and photoluminescence (PL) spectroscopies.

\section{Results and discussions}

The covalent bonding between OLC phase and silicon diimide backbone is of critical importance for a good dispersion and avoidance of agglomeration of carbon phase as well as for a strong synergistic effect of both composing phases, resulting in an efficient interphase as well and a strong interfacial bond formation. Thus, methods such as FTIR (Figure 2a) and Raman (Figure 2b) spectroscopies provide details on the formation of amide bridges in-between OLC nanoparticles (of $\sim 5 \mathrm{~nm}$ in size as previously reported by Wang et al., 2016) and the silicon atoms in the polymeric matrix (see Figure 1). UV-Vis and PL spectroscopies were applied in order to identify the electronic transitions due to defect luminescence mechanism in the composites (Farhan et al., 2017; Kozák et al., 2016).

As observed in Figure $2 b$, the results support the modification of the surface of the OLCs by introducing surface functional carboxylic groups, leading to the formation of higher number of surface defects in the case of functionalized OLCs, as compared with pristine OLCs (Nguyen et al., 2011; Tripathi et al., 2016). Silicon diimide is highly sensitive to moisture contamination. Short exposure to air results in the reaction of moisture with the Si-NH-Si units, thus forming siloxane and gaseous byproduct $\mathrm{NH}_{3}$. The reactive chlorine end-groups of silicon diimide react immediately with ammonia to form $\mathrm{NH}_{4} \mathrm{Cl}$, as
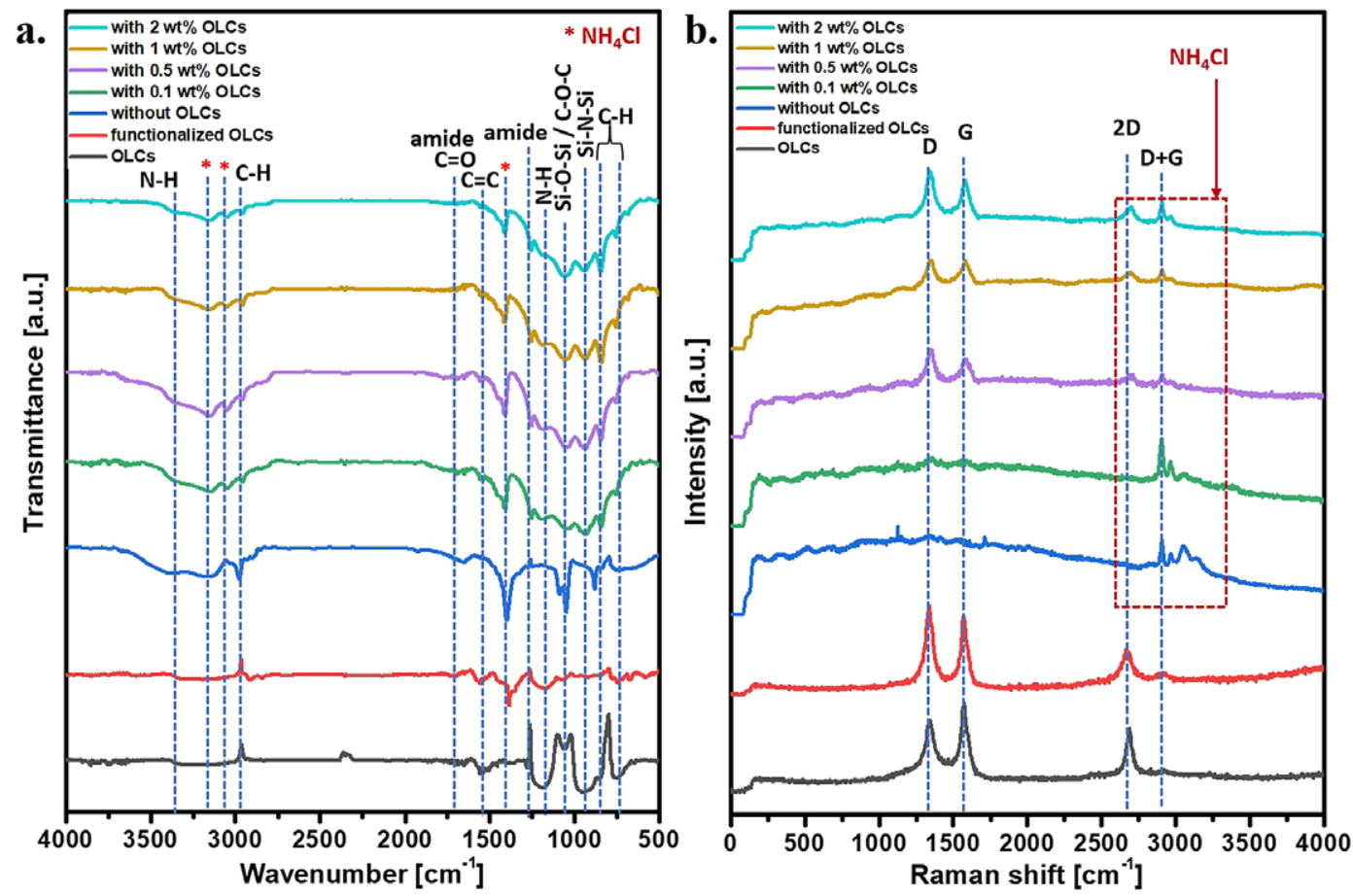

Figure 2. (a) Fourier transform infrared spectra (left) and (b) Raman spectra (right) of onion-like carbons (OLCs), functionalized OLCs, and OLCs-silicon diimide polymer composites with different contents of OLCs. 
observed in Figure 2b ( Vu et al., 2017). Besides - $\mathrm{Cl}$ end-groups, $-\mathrm{Si}\left(\mathrm{CH}_{3}\right)_{3}$ functionalities are also observed in the FTIR spectra of the composites.

According to FTIR- and UV-Vis/NIR-data, functionalized OLCs react with -HN-Si backbone, leading to the formation of expected amide $(\mathrm{O}=\mathrm{C}-\mathrm{N}<)$ interfacial bondings (Hetmann et al., 2018; Roguska et al., 2011). Thus, the presence of amide bridges underlines the covalent nature of the interface between OLCs and silicon diimide in the composites.

Rather few papers have been reported on the optical properties of silicon diimide polymers. It can be concluded from Figure 3 that the UV absorbance and the PL-quenching of OLCs-silicon diimide polymer composites depend on the content of functionalized OLCs. The reduction of PL peaks is likely due to the presence of defects in the composites (Kozák et al., 2016). The Si and N dangling bonds in silicon diimide form a trap-level state and the recombination center participates in radiative transitions resulting in luminescence (Farhan et al., 2017). The presence of functionalized OLCs in OLCs-silicon diimide polymer composites creates new emissive deep traps, which act as luminescent trapping sites for the excitation energy, and affect the radiative $\mathrm{e}-\mathrm{h}$ recombination processes by the relaxation-related spectral migration.

\section{Conclusions}

In conclusion, we presented a simple synthesis method for OLCs-silicon diimide composites with different contents of $0 \mathrm{D}$ nanocarbons, where the strong synergistic effect of the component phases is demonstrated by the PL study. Thus, chemically functionalized OLCs were successfully embedded by strong interfacial $\mathrm{O}=\mathrm{C}-\mathrm{N}<$ covalent bonds within the organosilicon polymer matrix. Due to their facile preparation method and promising properties, the polymer nanocomposites reported herein may be
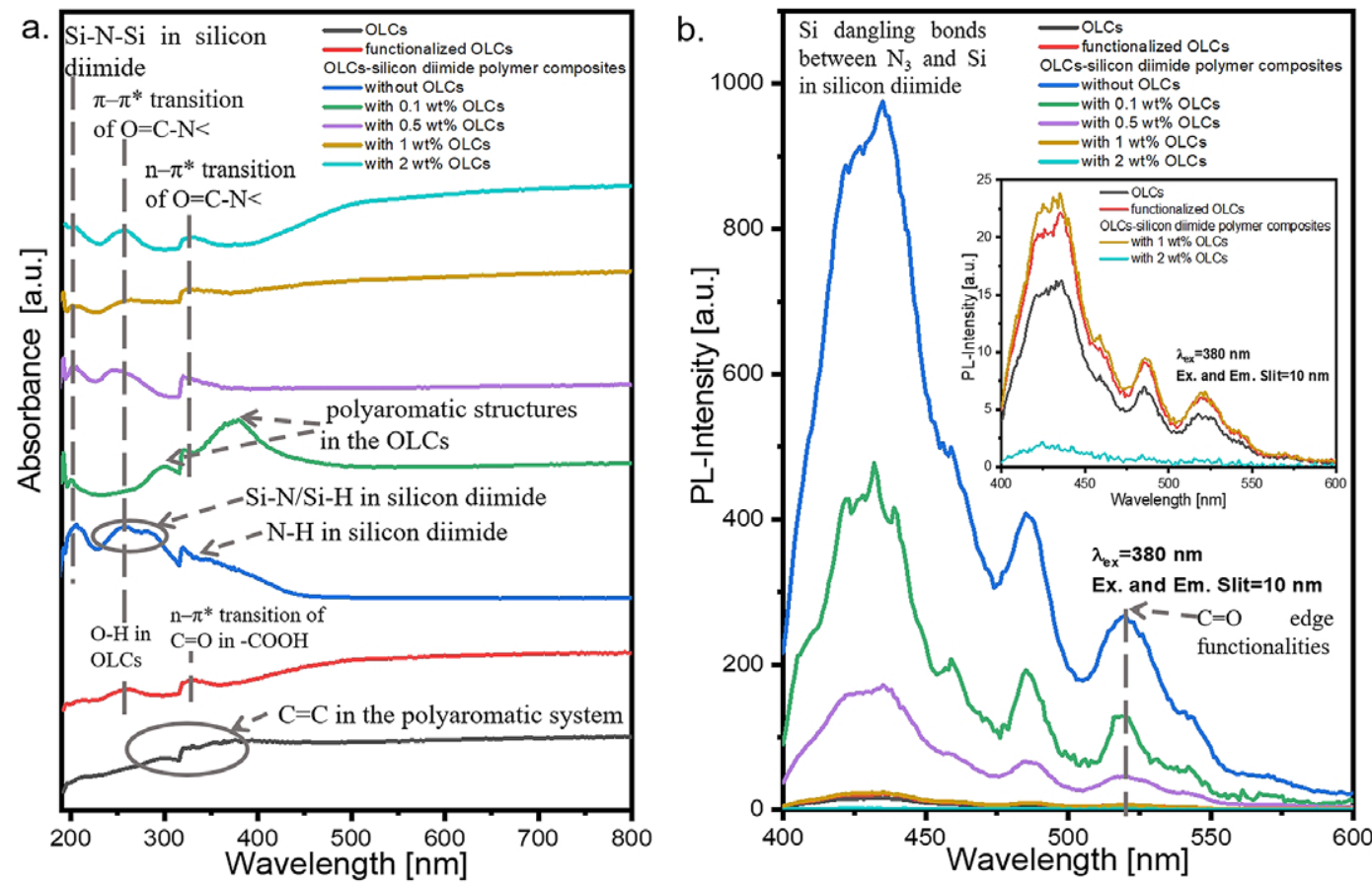

Figure 3. (a) UV-Vis/NIR spectra (left) and (b) PL emission spectra (right) of OLCs, functionalized onion-like carbons (OLCs) and OLCs-silicon diimide polymer composites with different contents of OLCs. All PL spectra were excited at the wavelength of $380 \mathrm{~nm}$ and with the excitation- and emission-slit of $10 \mathrm{~nm}$. The insets show the PL emission spectra of OLCs, functionalized OLCs and the polymer composites with 1 and $2 \mathrm{wt} \%$ OLCs. 
applied as suitable precursors for a novel class of "smart" 0D-nanocarbon-containing ceramic composites with custom-made structural features and multifunctional properties for various purposes, such as thermal management or environmental applications.

Authorship contributions. K.W. performed the experimental work, analyzed the data, and wrote the manuscript. G.M. mentored, designed the experiments, and edited and revised the manuscript.

Funding statement. This work was supported by the German Research Foundation DFG (Eigene Stelle, grant number IO $83 / 2-1)$

Conflicts of interest. The authors declare no conflicts of interest.

Data availability statement. The data that support the findings of this study are available from the corresponding author, G.M., upon reasonable request.

\section{References}

Balázsi, C. (2010). Development of multifunctional silicon nitride based nanocomposites. MSF, 659, 121-126. http://dx.doi. org/10.4028/www.scientific.net/MSF.659.121

Balazsi, C. (2012). Silicon nitride composites with different nanocarbon additives. Journal of the Korean Ceramic Society, 49, 352-362. http://dx.doi.org/10.4191/kcers.2012.49.4.352

Bartelmess, J., \& Giordani, S. (2014). Carbon nano-onions (multi-layer fullerenes): Chemistry and applications. Beilstein Journal of Nanotechnology, 5, 1980-1998. http://dx.doi.org/10.3762/bjnano.5.207

Butsyk, O., Olejnik, P., Romero, E., \& Plonska-Brzezinska, M. E. (2019). Postsynthetic treatment of carbon nano-onions: Surface modification by heteroatoms to enhance their capacitive and electrocatalytic properties. Carbon, 147, 90-104. http:// dx.doi.org/10.1016/j.carbon.2019.02.063

Colombo, P., Mera, G., Riedel, R., \& Sorarù, G. D. (2010). Polymer-derived ceramics: 40 years of research and innovation in advanced ceramics. Journal of the American Ceramic Society, 93, 1805-1837. http://dx.doi.org/10.1111/j.15512916.2010.03876.x

Farhan, S., Wang, R., Zhang, D., \& Li, K. (2017). By-product processing of $\mathrm{Si}_{3} \mathrm{~N}_{4}$ saw-tooth nanoribbons during carbon foam processing using pyrolysis-nitridation reactions. CrstEngComm, 19, 5432-5441. http://10.0.4.15/C7CE01121K

Hetmann, A., Wujak, M., Bolibok, P., Zięba, W., Wiśniewski, M., \& Roszek, K. (2018). Novel biocatalytic systems for maintaining the nucleotide balance based on adenylate kinase immobilized on carbon nanostructures. The Korean Journal of Counseling and Psychotherapy, 88, 130-139. http://dx.doi.org/10.1016/j.msec.2018.03.006

Kozák, O., Sudolská, M., Pramanik, G., Cígler, P., Otyepka, M., \& Zbořil, R. (2016). Photoluminescent carbon nanostructures. Chemistry of Materials, 28, 4085-4128. http://dx.doi.org/10.1021/acs.chemmater.6b01372

Krüger, A. (2010). Carbon onions and related materials. In Carbon materials and nanotechnology (pp. 283-327). John Wiley \& Sons. http://dx.doi.org/10.1002/9783527629602.ch4

Kuznetsov, V. L., Chuvilin, A. L., Butenko, Y. V., Mal'kov, I. Y., \& Titov, V. M. (1994). Onion-like carbon from ultra-disperse diamond. Chemical Physics Letters, 222, 343-348.

Mcdonough, J., \& Gogotsi, Y. (2013). Carbon onions: Synthesis and electrochemical applications. Electrochemical Society Interface, 22, 61-66. http://dx.doi.org/10.1149/2.F05133if

Mera, G., Gallei, M., Bernard, S., \& Ionescu, E. (2015). Ceramic nanocomposites from tailor-made preceramic polymers. Nanomaterials, 5, 468-540.

Mera, G., \& Ionescu, E. (2013). Silicon-containing preceramic polymers. Encyclopedia of Polymer Science and Technology, 12, 432-464. http://dx.doi.org/10.1002/0471440264.pst591

Mera, G., \& Ionescu, E. (2019). Polymer-derived ceramics. In Encyclopedia of inorganic and bioinorganic chemistry (pp. 1-26). John Wiley \& Sons. http://dx.doi.org/10.1002/9781119951438.eibc2705

Mera, G., Navrotsky, A., Sen, S., Kleebe, H.-J., \& Riedel, R. (2013). Polymer-derived SiCN and SiOC ceramics - Structure and energetics at the nanoscale. Journal of Materials Chemistry A, 1, 3826-3836. http://dx.doi.org/10.1039/c2ta00727d

Mohamed, M., Chehimi, M., \& Pinson, J. (2013). Applied surface chemistry of nanomaterials. Nova Science.

Mykhailiv, O., Zubyk, H., \& Plonska-Brzezinska, M. E. (2017). Carbon nano-onions: Unique carbon nanostructures with fascinating properties and their potential applications. Inorganica Chimica Acta, 468, 49-66. http://dx.doi.org/10.1016/ j.ica.2017.07.021

Nguyen, T. T., Nguyen, S. U., Phuong, D. T., Nguyen, D. C., \& Mai, A. T. (2011). Dispersion of denatured carbon nanotubes by using a dimethylformamide solution. Advances in Natural Sciences: Nanoscience and Nanotechnology, 2, 35015. http:// dx.doi.org/10.1088/2043-6262/2/3/035015

Ott, A., Rogg, S., Lauterbach, S., Kleebe, H.-J., Hess, C., \& Mera, G. (2020). Novel 0D-nanocarbon-silica ceramic composites: Sol-gel synthesis and high-temperature evolution. Dalton Transactions, 49, 7144-7154. http://dx.doi.org/10.1039/ d0dt01016b 
Plonska-Brzezinska, M. E. (2019). Carbon nano-onions: A review of recent progress in synthesis and applications. ChemNanoMat, 5, 568-580. http://dx.doi.org/10.1002/cnma.201800583

Riedel, R., Mera, G., Hauser, R., \& Klonczynski, A. (2006). Silicon-based polymer-derived ceramics: Synthesis properties and applications - A review. Nippon Seramikkusu Kyokai gakujutsu ronbunshi, 114, 425-444. http://dx.doi.org/10.2109/ jcersj.114.425

Roguska, A., Pisarek, M., Andrzejczuk, M., Dolata, M., Lewandowska, M., \& Janik-Czachor, M. (2011). Characterization of a calcium phosphate- $\mathrm{TiO}_{2}$ nanotube composite layer for biomedical applications. Materials Science and Engineering: $C$, 31, 906-914. http://dx.doi.org/10.1016/j.msec.2011.02.009

Tripathi, K. M., Bhati, A., Singh, A., Gupta, N. R., Verma, S., Sarkar, S., \& Sonkar, S. K. (2016). From the traditional way of pyrolysis to tunable photoluminescent water soluble carbon nano-onions for cell imaging and selective sensing of glucose. RSC Advances, 6, 37319-37329. http://10.0.4.15/C6RA04030F

Vu, T. H., Hodyss, R., Johnson, P. V., \& Choukroun, M. (2017). Preferential formation of sodium salts from frozen sodiumammonium-chloride-carbonate brines - Implications for Ceres' bright spots. Planetary and Space Science, 141, 73-77. http:// dx.doi.org/10.1016/j.pss.2017.04.014

Wang, K., \& Mera, G. (2021). Preparation of onion-like carbon-silicon diimide polymer composites. protocols.io. https:// dx.doi.org/10.17504/protocols.io.bs62nhge

Wang, X., Mera, G., Morita, K., \& Ionescu, E. (2016). Synthesis of polymer-derived graphene/silicon nitride-based nanocomposites with tunable dielectric properties. Journal of the Ceramic Society of Japan, 124, 981-988. http://dx.doi.org/ 10.2109/jcersj2.16089

Weinmann, M., Ionescu, E., Riedel, R., \& Aldinger, F. (2013). Chapter 11.1.10: Precursor-derived ceramics. In Handbook of advanced ceramics (pp. 1025-1101). Elsevier.

Zeiger, M., Jäckel, N., Mochalin, V. N., \& Presser, V. (2016). Review: Carbon onions for electrochemical energy storage. Journal of Materials Chemistry A, 4, 3172-3196. http://10.0.4.15/C5TA08295A

Cite this article: Wang K, Mera G (2021). Chemical design of onion-like carbon-silicon diimide polymer composites Experimental Results, 2, e27, 1-10. https://doi.org/10.1017/exp.2021.13 


\title{
Peer Reviews
}

\section{Reviewing editor: Dr. Emre Erdem}

Sabanci University, Materials Science and Nanoengineering, Sabanci University Tuzla campus, Istanbul, Turkey, Istanbul, Turkey, 34956

This article has been accepted because it is deemed to be scientifically sound, has the correct controls, has appropriate methodology and is statistically valid, and has been sent for additional statistical evaluation and met required revisions.

doi:10.1017/exp.2021.13.pr1

\section{Review 1: Chemical Design of Onion-like Carbon-Silicon Diimide Polymer Composites}

Reviewer: Dr. Rükan Genc

Date of review: 26 April 2021

\begin{abstract}
(c) The Author(s), 2021. Published by Cambridge University Press. This is an Open Access article, distributed under the terms of the Creative Commons Attribution licence (http://creativecommons.org/licenses/by/4.0), which permits unrestricted re-use, distribution and reproduction, provided the original article is properly cited.
\end{abstract}

Conflict of interest statement. Reviewer declares none

\section{Comment}

Comments to the Author: Manuscript No. EXP-21-0016

Title: Chemical Design of Onion-like Carbon-Silicon Diimide Polymer Composites

Authors: Kaili Wanga and Gabriela Mera

The research article reported by Wanga and Mera presents a synthesis route for the synthesis of a polymer composite based on onion-like carbons (OLCs)-silicon diimide. The topic covered is interesting however the manuscript is poorly written, not structured logically, language needs improvement as most sentences are unfortunately written with poor English. This problem with the language makes it difficult to read, understand and review.

I have my suggestions listed below about this paper, and I, unfortunately, recommend it not to be published in its current form.

\section{Abstract:}

Article required to be re-written. For example in the following sentences taken from the abstract: "The preparative access to a novel class of polymer composites based on onion-like carbons (OLCs)-silicon diimide by a salt-free polycondensation reaction, it is reported. The pyridine-catalyzed polymerization reaction in the presence of various contents $(0.1,0.5,1$ and $2 \mathrm{wt}$. \%) of carboxyl-functionalized OLCs in argon atmosphere, it provides composites with well-dispersed and covalently incorporated 0D nanocarbon throughout the 3D matrix of silicon diimide polymer", it is difficult to understand what authors try to explain. The sentence in its current form does not make sense.

\section{Introduction:}

Same for another example is the first paragraph of the introduction, one can understand what authors try to tell, but the linguistic structure of the sentences is wrongly built: 
"In the search for novel precursors for silicon nitride-based polymer-derived ceramic materials ( $\mathrm{Si} 3 \mathrm{~N}$ 4 - PDCs) with high mechanical, thermal and electrical properties, several synthesis routes have been reported in the last 30 years"

In the following sentence, authors should clarify the term "strong covalent bonding", covalent bonding between which components or molecules? what are the relationships between a stronger bond formation and a stronger interface as a result? Which interface do authors mean?

"Chemical functionalization of nanocarbons nanocarbon surfaces offers the possibility to of developing advanced polymer composites with strong covalent bonding (strong interface), and excellent dispersion of nanocarbon phase in the matrix (Ott et al., 2020; Mohamed et al., 2013).

Authors claimed as "Thus, classical challenge of agglomeration of nanocarbons in the polymer matrix can be solved." Authors should put a stronger hypothesis in the introduction and put some more literature supporting their way should be added.

Objectives:

In the first sentence of the section "The main objective is to provide a chemical facile access to novel 0D-nanocarbon-containing Si $3 \mathrm{~N}$ 4-based PDCs precursors, based on onion-like carbons (OLCs) (Bartelmess and Giordani, 2014; Butsyk et al., 2019; Krüger, 2010; Kuznetsov et al., 1994; Mcdonough and Gogotsi, 2013; Mykhailiv et al., 2017; Plonska-Brzezinska, 2019; Zeiger et al., 2016) -silicon diimide polymer composites." What do authors mean with "chemical facile access"? and "authors should either use 0D nanocarbon containing Si $3 \mathrm{~N}$ 4-based PDCs precursors or onion-like carbons -silicon diimide in one sentence.

In the objective section, the article hypothesis and sub-objectives/goals, reasons, should be discussed in detail, and methods of the article should be taken out from this section and put to methods section as authors re-presented them in the methods section.

Methods:

Materials and types of equipment should be listed pointing out the supplier and models. How do authors optimize the optimum reaction times and temperatures and concentrations?

Results and discussion

On page 5, authors claim that "As observed in Figure 2, the results support the modification of the surface of the OLCs by introducing surface functional carboxylic groups, leading to the formation of a higher amount of surface defects in the case of functionalized OLCs, in comparison with pristine OLCs". How the results given in figure 2 can be interpreted as the sample has high amount of defects?

In the following sentence "According to Raman spectra in Figure 2b, the moisture contamination by the measurement in air may influence the rearrangements and further crosslinking of Si-Cl polymer endgroups and Si-NH-Si backbone leading to the formation of $\mathrm{NH} 4 \mathrm{Cl}$ ", it is difficult to understand what authors mean to discuss. A more explanatory discussion referring to the changes in RAMAN and FTIR spectra needed.

The authors also claimed as "The reduction of the PL peaks is likely due to defects present in the composites" Effect of decreased distance between nanoparticles due to increased concentration and covalent bonding on the PL quenching should also be taken into account.

The authors have not discussed the effect of OLC concentration on the formed composites.

Authors needed to show the particle size with DLS and TEM or SEM imaging together with the SEM images of the final composite produced.

Conclusions

As prepared materials are humidity sensitive, and thus, their further use needs attention. Do authors have any recommendations for ensuring the wider use of the as-prepared composites? 


\section{Score Card}

Presentation

3.0

Is the article written in clear and proper English? (30\%)

Is the data presented in the most useful manner? (40\%) 3/5

Does the paper cite relevant and related articles appropriately? (30\%) 3/5

\section{Context}

2.8

Does the title suitably represent the article? (25\%)

Does the abstract correctly embody the content of the article? (25\%)

Does the introduction give appropriate context? (25\%)

Is the objective of the experiment clearly defined? $(25 \%)$

Analysis

Are the limitations of the experiment as well as the contributions of the experiment clearly outlined? (20\%) 


\section{Review 2: Chemical Design of Onion-like Carbon-Silicon Diimide Polymer Composites}

Reviewer: Dr. Özge Balci (D)

Koc Universitesi, Istanbul, Turkey, 34450

Date of review: 07 May 2021

(C) The Author(s), 2021. Published by Cambridge University Press. This is an Open Access article, distributed under the terms of the Creative Commons Attribution licence (http://creativecommons.org/licenses/by/4.0), which permits unrestricted re-use, distribution and reproduction, provided the original article is properly cited.

Conflict of interest statement. Reviewer declares none

\section{Comment}

Comments to the Author: This study reports the synthesis of OLCs-silicon diimide composites with different contets of OD nanocarbon. Photoluminescence studies were done to observe the synergistic effect of the component phases. The preparation method and the final properties are interesting in terms of the design of advanced and multifunctional nanocomposites. I suggest some minor revisions before publication:

- Schlenk technique used in the experimental studies should be described in more detail by giving a schematic diagram of the setup. The modifications to the published report (Wang et al., 2016) may be explained. If the same process is used, the novel part of this study should be explained in terms of the used preparation method.

- The observed streching bands in the FTIR spectra (Fig.2a) is not explained. The authors need to evaluate the FT-IR results and improve the discussion part for Fig.2.

\section{Score Card}

Presentation

Is the data presented in the most useful manner? (40\%)

Does the paper cite relevant and related articles appropriately? (30\%)

\section{Context}

Does the abstract correctly embody the content of the article? (25\%)

Does the introduction give appropriate context? (25\%)

Is the objective of the experiment clearly defined? (25\%)

Are the limitations of the experiment as well as the contributions of the experiment clearly outlined? (20\%) 